\title{
Optimal Reconfiguration of Radial Distribution Networks using Improved Genetic Algorithm
}

\author{
A. S. Abubakar*, K. R. Ekundayo, A. A. Olaniyan \\ Department of Electrical Engineering, Ahmadu Bello University, Zaria Nigeria.
}

\begin{abstract}
Reconfiguration of an electrical power radial distribution network is aimed at finding a radial operating structure that minimizes the system active power loss, enhancing the system voltage profile via reducing the active power losses whilst satisfying operating constraints is one of the most important measures of improving the operational performance of a distribution system. In this paper, an efficient approach to solving the problem of reconfiguration considering active power loss, total voltage deviation for a typical distribution network. The method developed is based on improved genetic algorithm to determine the optimal location of tie and sectionalizing switches, with a view to yield an optimal performance for the network. The reconfiguration model was implemented using MATLAB R2016a simulation environment. The effectiveness and validity of the proposed model was tested on a 16, 33 and 69 IEEE-Bus standard systems for distribution network. The results show that with a reduction of $8.86 \%, 31.15 \%$ and $53.53 \%$ in active power loss as compared to the initial configuration, whilst a total voltage deviation of 0.0284 p.u., 0.0622 p.u and 0.0517p.u for 16, 33 and 69 IEEE Bus respectively.
\end{abstract}

KEYWORDS: System reconfiguration, Switching state, Power loss, Genetic algorithm, Distribution system.

[Received January 20, 2018; Revised June 06, 2018; Accepted August 10, 2018]

Print ISSN: 0189-9546 | Online ISSN: 2437-2110

\section{INTRODUCTION}

An electrical distribution system (DS) is the last stage of electrical energy supply chain in power system operation whereby electricity is being distributed to individual customers through a radial network. During power distribution, the system experiences a lot of technical losses, primarily power loss (Anil et al., 2010). Power loss significantly affect the quantity and quality of power delivery to the consumers most especially in a large-scale distribution network where power loss accounted for $70 \%$ of the total losses in the system (Badran et al., 2017). Chandramohan et al., in 2010 estimated that the cost of operational losses in distribution system was amounted to USD 5,851.85 and this was majorly attributed to power system losses. Technically, power losses reduce the total voltage profile of the network especially in heavily loaded systems (Anil et al., 2010). The problem of minimizing distribution systems losses has been a major focus for researchers and utility companies due to the need for better quality of service and better utilization of available energy (Flaih et al., 2017).

Over the last three decades, researchers and utility companies in the area of distribution systems automation and control have developed and utilized different techniques for reducing losses within the power distribution system level, these approaches include load balancing, capacitor placement, introduction of higher voltage level, reconductoring, reconfiguration etc., (Sarfi \& Chikhani, 1994; Abdelaziz et al., 2012).

Though, the methods of reducing losses in DS are quite numerous but the major concern when adopted is about their technical implications on the network both in engineering side

*Corresponding author: abubakaras@abu.edu.ng and financial perspectives. For instance, the introduction of new equipment at distribution level offers tremendous financial burden on the utilities and this cannot be justified by potential saving. Also, the use of fixed compensators offers optimal reduction in losses for specific demand condition but requires an efficient control system which is expensive (Abubakar et al., 2015; Sarfi \& Chikhani, 1994). The choice of reconductoring is not an option due to the financial implication and time requires for relaying new feeders which might affect system availability and the quality of service. In addition, the introduction of higher voltage level requires upgrading the rating of the transformer and other equipment in the network (Duan et al., 2015; Badran et al., 2017; Sarfi \& Chikhani, 1994).

The utilization of reconfiguration of distribution system network approach to solve the problem of power losses has been employed in this work due to its flexibility in accommodating different objective function, ability to use existing equipment and as well as its other practical advantages to offer dynamic means of reducing losses and improving voltage within the distribution system. Distribution systems are designed as radial systems in which tie (NO) and sectionalizing switches(NC) play a critical role in determining the configuration of the system (Rasthechi \& Pashai, 2012). Therefore, the process of reconfiguration of distribution system network is done by altering the feeder topological structure (i.e. exchanging the functional links between its elements) in order to effectively manage the open/close status of sectionalizing and tie-switches in the system under contingencies as well as under normal operating conditions (Badran et al., 2017; Abubakar et al., 2015; Prasad et al., 
2005). With the deregulation of power sector across the globe, the need to enjoy better quality of service are the major priority of consumers while enhancing the performance of distribution system automation to provide better utilization of available energy while satisfying all systems' operating constraints becomes outermost concerns of many utility companies, researchers and electrical engineers.

Reconfiguration of distribution system is a complex combinatorial, non-differentiable constrained optimization problem due to the candidate switching combinations (Duan et al., 2015; Abubakar et al., 2015). And a lot of algorithms have been developed and applied by many researchers to solve reconfiguration problem these includes branch and bound techniques, analytic approach, heuristic approach, expert system, linear programming, artificial intelligence etc. The earlier researches (Nara et al., 1992; Baran \& Wu, 1998; Abdelaziz et al., 2012) on network reconfiguration formulated the problem as a single objective function aimed at reducing the active power losses in the network. However, the major challenges with these works is that their results do not guarantee an effective solution thus increasing the possibility of been trapped into local minima.

Reconfiguration problem is one of the multi criteria and multi objective optimization types, where the solution is chosen after the evaluation of some indices such as active power loss, reliability indices, branch load limit, expected energy not served and voltage drop limit which represent multiple functions. These criteria can be grouped into objective functions that can be minimized subjected to some constraints that must be included with some bounds. The works of (Huang 2012; Kumar et al., 2006; Royteleman et al., 1995) addressed the problem using multi-objective approach. The major limitations of some of these approaches are transforming the multiple cost function into single objective function by using weighted parameter which are highly subjective, thus avoiding the complexity associated in solving a typical multi-objective problem. The inclusion and increasing penetration of distributed energy sources to distribution network, has necessitated the need to consider other parameters that are critical to the network (total voltage deviation, reliability index, expected energy not served etc.) (Abubakar et al., 2015).

Merlin et al. (1975) was the first to propose a heuristic approach for reconfiguration of distribution system network with a focus on minimization of line loss. The problem was formulated as an integer mixed non-linear optimization problem using a discrete branch-and-bound technique to generate a branch with least current solution. The work of (Prasad et al., 2005; Duan et al., 2015; Le Roux, 2013) developed an approached based on a generic algorithm for optimal reconfiguration of radial distribution systems network (RDSN). The major challenges with this works a random set of chromosomes was used to represent the status of all the switches (Tie and sectionalizing switches) in the network, thus adding to the computation complexity of the technique. The work of Le Roux, 2013 and Mendoza et al., 2006 adopted New Raphson power flow to estimate the initial losses of the network which may not produce an accurate result due to ill condition and poor convergence. The work developed an improved crossover operator of the GA via a multi-objective function, whilst considering the number of open switches (Tie) as the random generated chromosomes and employed the use of forward and backward sweep process for load flow analysis. The effectiveness of the proposed method was demonstrated and implemented on a balance 33-bus, 69-bus and 136-bus IEEE test system and the obtained results showed that the proposed method can solve the feeder reconfiguration more efficiently with less iteration and fewer time.

The rest of this work is organized as follows: Section II formulate the problem of reconfiguration, section III, described the concept of the genetic algorithm optimization technique. Section IV detail of the developed methodology, Section V Implementation of the developed approach using 16, 33, and 69-Bus standard IEEE test system. Section VI details result, discussion and conclusion.

\section{FORMULATION OF THE PROBLEM}

This work adopted the use of active power loss for:

\section{A. Minimization of total power losses,}

\section{(A). Minimization of Total Power Losses}

The power loss reduction is the primary aim of the reconfiguration of the distribution system. Hence it is considered as the main objective function. The power loss reduction can be expressed in terms of current variable by using:

$$
P_{\text {Loss }}=\min \sum_{i=1}^{N-1} k I^{2}(i) R(i)
$$

\section{Subject to Constraints}

i. Total voltage deviation

$V_{\min } \leq V_{(i)} \leq V_{\max } ; n \in\{1,2, \ldots, N\}$

ii. Branch current limit

$I_{\min } \leq I_{(i)} \leq I_{\max } ; n \in\{1,2, \ldots, N\}$

iii. Power Flow constraint

$$
f\left(P_{i}, Q_{i}, V_{i}, \theta_{i}\right)=0
$$

iv. Radial structure constraint

where $V_{\text {min }}$ and $V_{\text {max }}$ denote minimum and maximum specified limits for the node voltages and $I_{\min }$ and $I_{\max }$ are the line ampacity of the $i^{t h}$ line of the distribution network.

\section{GENERIC ALGORITHM}

Genetic Algorithms is a meta-heuristic technique based on the Theory of Evolution and is characterized as derivative free population-based stochastic optimization method inspired by the concept of natural selection and evolutionary process. The GAs search technique used initialized with probabilistic selection of population based on their fitness and searches for optima by updating generations (Gupta et al., 2014). The three main operators of selection in GA are crossover as a principal operator for selecting a random position in the parents' strings and swapping the characters either left or right of this point 
with each other. Mutation as a secondary operator to random modification of a string position by changing " 0 " to " 1 " or vice versa, with a small probability. Elitism is used to preserve the elite child, i.e., the individuals with the best fitness in the current generation.

Each individual in the population represents a possible solution and is termed a "chromosome". A chromosome is coded as a genetic string containing the locations of open switches in the power distribution network. Each chromosome is assigned a lifetime parameter at its creation. The necessity for an optima radial operating configuration makes it more problematic to formulate a mathematical model efficiently for solution which makes codification of a meta-heuristic techniques a better solution used to solve the network reconfiguration problem (i.e. for codification of GA, the individuals are represented by a string of normally opened SW number.

Accordingly, the length of the string is in accordance with the number of the loop path in the system. The general structure of the GA used can be summarized as follows (Carreno et al., 2008; Duan et al., 2015):

Step 1: Generate the initial population and find the fitness and unfitness for each individual in it.

Step 2: Select two individuals as parents using tournament selection.

Step 3: Apply genetic operators depending on the problem (crossover, mutation, etc.) to generate a single descendant.

Step 4: Local search optimization: improve the resulting descendant with information about the nature of the problem.

Step 5: Include the descendant in the population, only if it passes a substitution test.

Step 6: If the stop criterion was satisfied, stop. Otherwise, return to step 2 .

\section{THE DEVELOPED APPROACH}

The methodology adopted for this work is based on selective enhanced genetic algorithm optimization technique, due to its robustness and the need for selecting few parameters. In the proposed codification some rules have been framed to create only feasible individuals during initialization and also to correct the infeasible individuals as and when appear throughout the search process. The developed approach is similar to the work of (Gupta et al., 2014; Le Roux, 2013; Abdelaziz, 2017) but consider all the tie switches regarding of their duplication in any loop described as follows.

Principal node: The junction of three or more elements of the distribution network graph (DNG).

Exterior node: The node located at the perimeter of the DNG.

Interior node: The node located inside the perimeter of the DNG.

Loop vector: It is the set of elements constituting closed path in a DNG.

Common branch vector: It is the set of elements which are common between any two loop vectors of a DNG.

Prohibited group vector: It is the set of common branch vectors, from each of them if one element is opened then one or more interior nodes of the DNG will be islanded. The size of prohibited group vector cannot be greater than the total number of loop-vectors.

The following three rules have been suggested to ensure only feasible radial topologies at every stage of the genetic evolution.

Rule 1: Each candidate switch must belong to its corresponding loop vector.

Rule 2: Only one candidate switch can be selected from one common branch vector.

Rule 3: All the common branch vectors of a prohibited group vector cannot participate simultaneously to form an individual

The status of the normally open switches is considered and tested on a standard 16, 33 and 69-Bus IEEE distribution network as contained in Fig. 1. The detail steps are outlined as follows:

i. Close all tie switches or normally open switches to form a loop and or mesh network as shown in Table 1.

ii. Determination of possible branches that constitute each loop or mesh network.

iii. The number of branches in each loop constitute the search space dimension.

iv. Generation of random search space based on the numbers of element in each loop or dimension.

v. Constraint checking is performed to ensure that generated chromosomes are void from loops and possible islanding. The constraint check comprises of checking for loops, islanding, searching the network to ensure that generated population have radial structure while ensuring load flow solution.

vi. Evaluation of the fitness functions as contained in equation (1) and (2).

vii. Include the descendant in the population, only if it passes a substitution test.

viii. Increase the number of iteration and perform steps ivvii.

ix. If the stopping criteria are meet, terminate process. 1.

The flowchart of the developed approach is shown in Fig.

\section{IEEE TEST SYSTEMS}

In order to ascertain the effectiveness of the approached, the developed algorithm was implemented and tested on a standard IEEE 16, 33 and 69-bus systems. The algorithm was implemented in MATLAB R2016a. For all these systems, the substation voltage is considered as 1 p.u. and all the tie and sectionalizing switches are considered as potential feasible switching candidate.

\section{Case 1: 16-bus Standard IEEE distribution}

The 16-bus IEEE test system shown in Fig. 2 is a distribution network which comprises of 3 feeders, 14 nodes and 15 lines, where 12 are sectionalizing switches (normally closed) and 3-tie switches (normally open) and the detail of the line and load data can be found in the work Le Roux, 2013. 


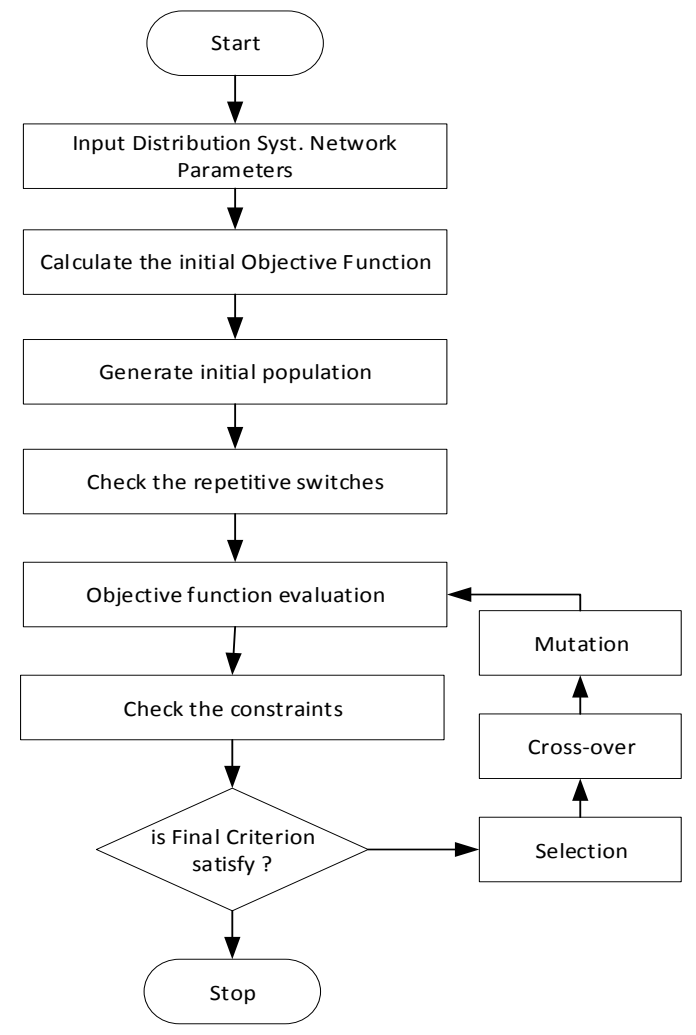

Fig. 1: Sequential Steps of the Developed Approach.

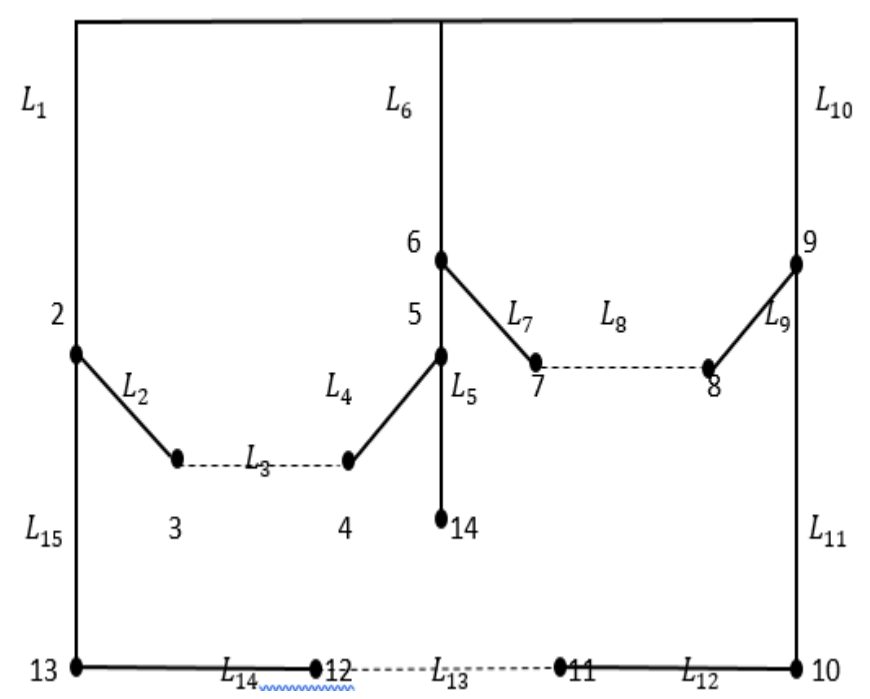

Fig. 2: Standard 16-Bus Distribution Network.

The number of branches that constitute the loops shown in Fig. 2 is contained in Table 1 and the simulation parameters used are: Population size $=10$, Number of generations $=3$, Mutation rate $=0.2$ and Selection rate $=0.3$.
Table 1: Number of Loops in standard 33-Bus Network.

\begin{tabular}{ll}
\hline Loop Number & Branches \\
\hline Loop1/Sd1 & $1,2,3,4,5,6$ \\
Loop2/Sd2 & $6,7,8,9,10$ \\
Loop3/Sd3 & $2,3,4,5,7,8,9,11,12,13,14,15$ \\
\hline
\end{tabular}

Case 2: 33-bus standard IEEE distribution

The test system as shown in Fig. 3 is a $100 \mathrm{MVA}, 12.66 \mathrm{kV}$, 33-bus standard IEEE distribution network comprises of 32 branches and 5-tie lines $(33,34,35,36,37)$, and the detail of the line and load data is contained in the work (Srinivasa \& Narasimham, 2009). The tie or normally open switch closed the number of branches that constitute the loops is contained in Table 2. The simulation parameters are similar to the work of (Le Roux, 2013; Mendoza et al., 2006).

Table 2: Number of Loops in standard 33-Bus Network.

\begin{tabular}{ll}
\hline Loop Number & Branches \\
\hline Loop1/Sd1 & $2,3,4,5,6,7,33,20,19,18$ \\
Loop2/Sd2 & $8,9,10,11,35,21,20,19,18,2,3,4,5,7$ \\
Loop3/Sd3 & $37,28,27,26,25,5,4,3,22,23,24$ \\
Loop4/Sd4 & $9,34,14,13,12,11,10$ \\
Loop5/Sd5 & $25,26,27,28,29,30,31,32,36,17,16,15,34,8$, \\
& 7,6 \\
\hline
\end{tabular}

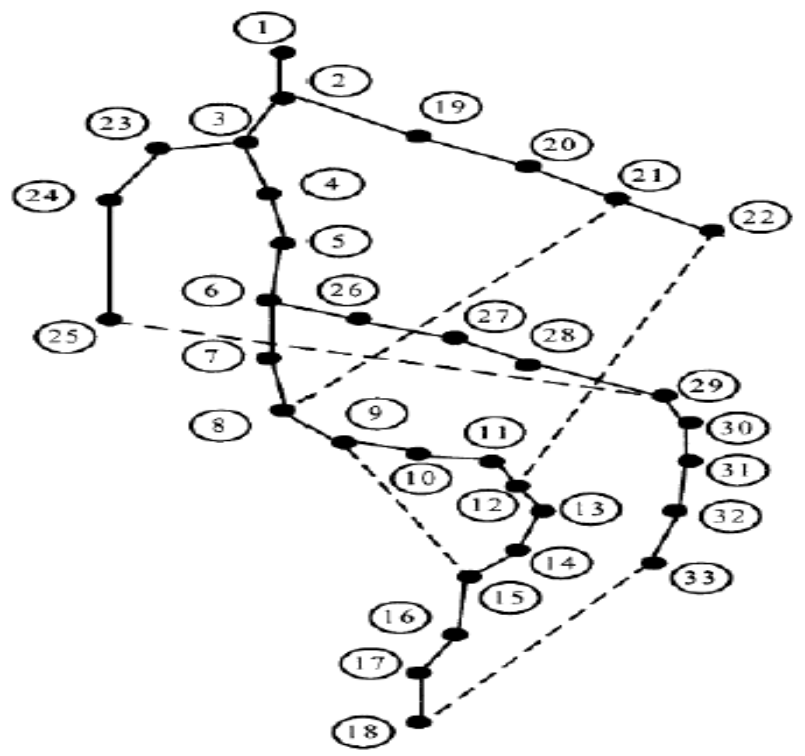

Fig 3: Standard 33-Bus Distribution Network.

\section{Case 3: 69-bus standard IEEE distribution}

The test system in this case is a 100MVA, $12.66 \mathrm{kV}$, IEEE 69-bus test system which is depicted in Fig. 4. The tie or normally open switch closed the number of branches that constitute the loops is contained in Table 2. From the figure, this system consists of 73 branches, 68 sectionalizing switches 
and 5 tie-lines switches (Baran \&Wu, 1989). This system has been considered by many researchers as a relatively large-scale system (Elsaiah \& Joydeep, 2015).

Table 3: Number of Loops in standard 69-Bus Network.

\begin{tabular}{ll}
\hline Loop Number & Branches \\
\hline Loop1/Sd1 & $36,37,38,39,40,41,42,43,51,52$ \\
Loop2/Sd2 & $44,45,46,69,68$, \\
Loop3/Sd3 & $14,15,16,17,18,19,20,21$ \\
Loop4/Sd4 & $5,6,7,8,9,53,54,55,56,57,58,59$ \\
Loop5/Sd5 & $22,23,24,25,26,27$, \\
\hline
\end{tabular}

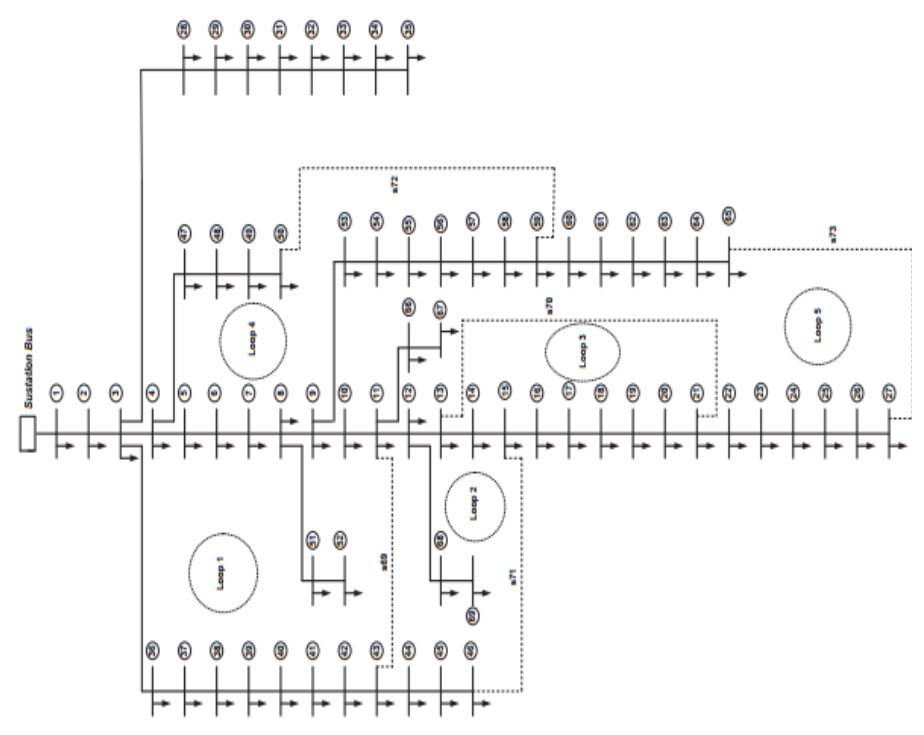

Fig. 4: Standard 69-Bus Distribution Network.

\section{DISCUSSION OF RESULTS}

Tables 4 and Fig. 5 present the optimal solution of 16-bus using the developed algorithm. Column 1 represents the number of tie switches, column 2 represents the optimal switches position, column 3 represents the active power loss, column 4 represents the $\max / \mathrm{min}$. voltage deviation and column 5 represent the computation time under all possible contingency conditions. Fig. 5 shows a plot of the active power loss as a function of number of 50 iteration for the 16-bus IEEE network. The optimal location of the tie switches was found to be 7,9 and 16, with reduction of $8.86 \%(466.1266 \mathrm{~kW})$ in active power loss as compare to the active power loss $(511.4356 \mathrm{~kW})$ of the initial configuration after reconfiguration. This reduction in active power loss is accompanied with an improvement in the total voltage deviation via a minimum voltage of $0.9716 \mathrm{~V}$ as compared to the initial configuration of $0.9693 \mathrm{~V}$. It is evident that the computation time for the developed enhanced GA method has been improved as detail in Table 7 .

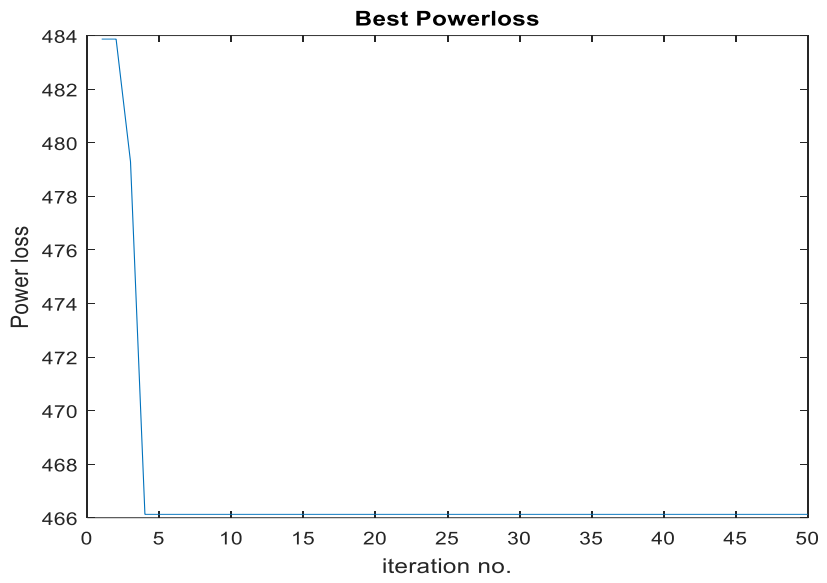

Fig. 5: Active power loss for 16-bus IEEE Network.

As seen in Table 5, after the developed algorithm was implemented in 33-bus IEEE system, the optimal location of the normally opened switches was found to be 7, 9, 14, 32 and 37 and there is a $31.15 \%(139.56 \mathrm{~kW})$ reduction in active power loss as compare to the active power loss $(202.71 \mathrm{~kW})$ of the base case after reconfiguration. Thus, Fig. 6 shows the result of the active power loss for 100 numbers of iterations.

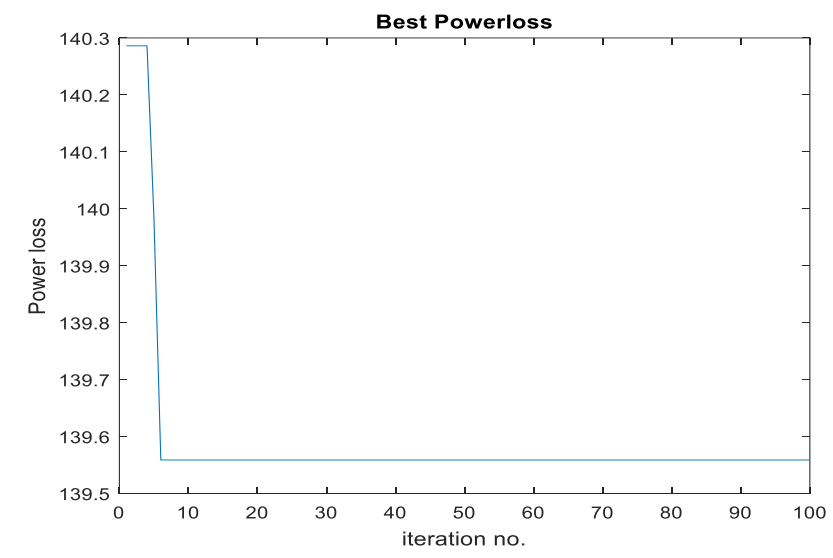

Fig. 6: Active power loss for 33-Bus IEEE Network.

Table 4: Optimal Solution Results of 16-Bus Test System.

\begin{tabular}{lllll}
\hline $\begin{array}{l}\text { 16-Bus } \\
\text { system }\end{array}$ & $\begin{array}{l}\text { Open } \\
\text { System Status } \\
\text { ing } \\
\text { Switches }\end{array}$ & $\begin{array}{l}\text { Active } \\
\text { Power } \\
\text { Loss } \\
(\mathbf{k W})\end{array}$ & $\begin{array}{l}\text { Voltages } \\
\text { (Max/Min. } \\
\text { value) }\end{array}$ & $\begin{array}{l}\text { Computatio- } \\
\text { nal Time } \\
\text { (sec) }\end{array}$ \\
\hline $\begin{array}{l}\text { Base Case } \\
\text { (original }\end{array}$ & $5,11,16$ & 511.435 & 0.9693 & ---- \\
$\begin{array}{l}\text { Configuration) } \\
\text { Proposed }\end{array}$ & $7,9,16$ & 466.126 & 0.9716 & 0.51 \\
$\begin{array}{l}\text { Configuration } \\
\text { Reduction }(\%)\end{array}$ & & 6 & & \\
\hline
\end{tabular}


Table 5: Optimal Solution Results of 33-Bus Test System.

\begin{tabular}{lllll}
\hline $\begin{array}{l}\text { 33-Bus } \\
\text { system } \\
\text { System Status }\end{array}$ & $\begin{array}{l}\text { Open } \\
\text { sectionalizing } \\
\text { Switches }\end{array}$ & $\begin{array}{l}\text { Active } \\
\text { Power } \\
\text { Loss } \\
(\mathrm{kW})\end{array}$ & $\begin{array}{l}\text { Voltages } \\
\text { (Max/Min. } \\
\text { value) }\end{array}$ & $\begin{array}{l}\text { Computational } \\
\text { Time }(\mathrm{sec})\end{array}$ \\
\hline $\begin{array}{l}\text { Base Case } \\
\text { Configuration }\end{array}$ & $\begin{array}{l}33,34,35, \\
36,37\end{array}$ & 202.71 & 0.9130 & ---- \\
$\begin{array}{l}\text { Proposed } \\
\text { Configuration }\end{array}$ & $\begin{array}{l}7,9,14,32, \\
\text { Reduction (\%) }\end{array}$ & 139.56 & 0.9378 & 13.12 \\
\hline
\end{tabular}

In addition, the optimal switching state for 69-bus network was found to be $10,14,58,63$ and 70 with a corresponding $53.53 \%(104.91 \mathrm{~kW})$ reduction in active power loss as compared to $224.91 \mathrm{~kW}$ base case after reconfiguration. The details of the results are summarized in Table 6 . However, it can be deduced that as the network complexity increases, the computation time will increase as can be observed by comparing these results with the 16 and 33 bus networks results. Thus, Fig. 7 shows the result of the active power loss for 100 number of iterations.

Table 6: Optimal Solution Results of 69-Bus Test System.

\begin{tabular}{|c|c|c|c|c|}
\hline $\begin{array}{l}\text { 69-Bus } \\
\text { system } \\
\text { System } \\
\text { Status }\end{array}$ & $\begin{array}{c}\text { Open } \\
\text { sectionalizi } \\
\text { ng Switches }\end{array}$ & $\begin{array}{c}\text { Activ } \\
\text { e } \\
\text { Powe } \\
\text { r Loss } \\
(\mathbf{k W})\end{array}$ & $\begin{array}{c}\text { Voltages } \\
\text { (Max/Min } \\
\text {. value) }\end{array}$ & $\begin{array}{l}\text { Computationa } \\
\text { I Time (sec) }\end{array}$ \\
\hline $\begin{array}{l}\text { Base Case } \\
\text { Configuration }\end{array}$ & $\begin{array}{c}69,70,71, \\
72,73\end{array}$ & $\begin{array}{c}224.9 \\
5\end{array}$ & 0.9092 & ---- \\
\hline $\begin{array}{l}\text { Proposed } \\
\text { Configuration }\end{array}$ & $\begin{array}{c}10,14,58 \\
63,70\end{array}$ & $\begin{array}{c}104.9 \\
1\end{array}$ & 0.9483 & 25.51 \\
\hline Reduction (\%) & & 53.53 & ---- & ---- \\
\hline
\end{tabular}

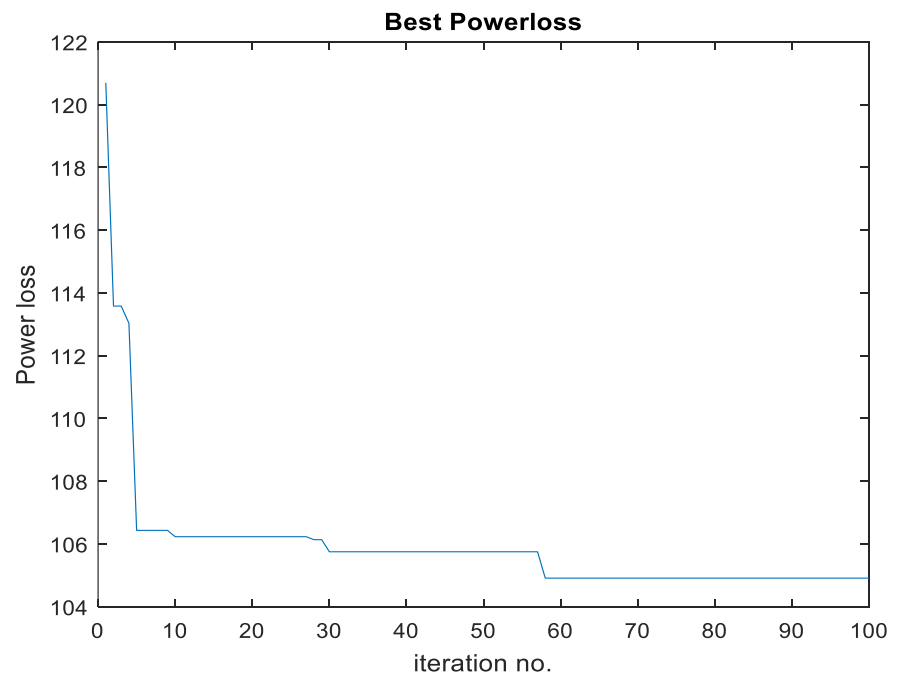

Fig. 7: Active power loss for 69-Bus IEEE Network.
Table 7: Summary of the Result Obtained.

\begin{tabular}{|c|c|c|c|c|c|}
\hline Network & Configuration & $\begin{array}{l}\text { Normally } \\
\text { Open } \\
\text { Switches }\end{array}$ & $\begin{array}{l}\text { Active } \\
\text { power } \\
\text { Losses }(k W)\end{array}$ & $\begin{array}{l}\text { Voltages } \\
\text { (Max/Min. } \\
\text { value) }\end{array}$ & $\begin{array}{l}\text { Comp } \\
\text { Time } \\
\text { (sec) }\end{array}$ \\
\hline $16 \mathrm{Bus}$ & Base case & $5,11,16$ & 511.4356 & 0.9693 & ---- \\
\hline IEEE & Proposed Case & $7,9,16$ & 466.1266 & 0.9716 & 0.51 \\
\hline \multirow[t]{2}{*}{ Network } & $\begin{array}{l}\text { Mendoza et } \\
\text { al., } 2006 \\
\text { (Traditional } \\
\text { G.A) }\end{array}$ & $17,18,19$ & 508.6227 & ---- & 0.93 \\
\hline & $\begin{array}{l}\text { Le-Roux et al., } \\
2012\end{array}$ & $4,7,13$ & 466.1 & 0.972 & 0.52 \\
\hline \multirow[t]{4}{*}{$\begin{array}{l}33 \text { Bus } \\
\text { IEEE }\end{array}$} & Base case & $\begin{array}{l}33,34,35 \\
36,37\end{array}$ & 202.71 & 0.9130 & ---- \\
\hline & Proposed Case & $\begin{array}{l}7,9,14,32, \\
37\end{array}$ & 139.56 & 0.9378 & 13.12 \\
\hline & $\begin{array}{l}\text { Mendoza et } \\
\text { al., } 2006 \\
\text { (Traditional } \\
\text { G.A) }\end{array}$ & $\begin{array}{l}7,9,14,32, \\
37\end{array}$ & 199.88 & ----- & 22.6 \\
\hline & $\begin{array}{l}\text { Le-Roux et al., } \\
2012\end{array}$ & $7,9,14,32,37$ & 139.55 & 0.937 & 13.42 \\
\hline \multirow[t]{2}{*}{$\begin{array}{l}69 \text { Bus } \\
\text { IEEE }\end{array}$} & Base case & $\begin{array}{l}69,70,71, \\
72,73\end{array}$ & 224.95 & 0.9092 & --- \\
\hline & Proposed Case & $\begin{array}{l}10,14,58, \\
63,70\end{array}$ & 104.91 & 0.9483 & 25.51 \\
\hline
\end{tabular}

\section{CONCLUSION}

This work developed a reconfiguration model using improved genetic algorithm. The developed approach was implemented on standard 16, 33 and 69 IEEE Bus Distribution and results validated via comparison with the works (Le Roux, 2013; Mendoza et al., 2006). The result shows that the developed is in conformity with other developed works with reduction in both active power loss and computational time with a corresponding increase in the minimum voltage for the 16, 33 and 69 IEEE test system as detailed in Table 7.

\section{REFERENCES}

Abdelaziz, J. A.; S. F. Mekhamer; M. F. Mohammed, and L. M. A. Badr. (2012), A Modified Particle Swarm Technique for Distribution System Reconfiguration. Open Access Journal on Electronic and Electrical Engineering, 1(1): 7-9.

Anil, S.; N. Gupta.and K. R. Niazi (2010). Minimal Loss Configuration for Large-Scale Radial Distribution Systems using Adaptive Genetic Algorithms. 16 ${ }^{\text {th }}$ National Power Systems Conference, Department of Electrical Engineering, Univ. College of Engineering., Osmania University, Hyderabad, A.P, India. 647-652.

Baran, M. E. and Wu, F. F. (1989). Optimal capacitor placement on radial distribution systems, IEEE Trans. Power Delivery, 4(1):725-735.

Carreno, E; R. Romero and P. Feltrin. (2008). An efficient codification to solve distribution network reconfiguration for loss reduction problem. IEEE Trans Power Syst; 23(4):1542-1551. 
Chandramohan, S.; N. Atturulu; R.K. Devi and B. Venkatesh. (2010). Operating cost minimization of a radial distribution system in a deregulated electricity market through reconfiguration using NSGA method. International Journal of Electrical Power, 32 (1): 126-132.

Duan, D. L.; L. Xiao-Dong; W. Xiao-Yue and Z. Bin. (2015). Reconfiguration of distribution network for loss reduction and reliability improvement based on an enhanced genetic algorithm. Journal of Electrical Power and Energy Systems, Elsevier Ltd. 64(1): 88-95

Elsaiah, S. and Joydeep, M. (2015). A Method for Minimum Loss Reconfiguration of Radial Distribution Systems. IEEE Trans on power system

Haupt, L; R. Ellen and S. Haupt. (2004). Practical Genetic Algorithms, Second Edition John Wiley Publication, 189-190.

Huang, C.Y. (2002). Enhanced Genetic Algorithmbased Fuzzy Multi-Objective Approach to Distribution Network Reconfiguration, IEEE Proc-Gener-Distrib, 149(1): 615-620.

Kumar, Y.; B. Das B. and J. Sharma. (2006). Service Restoration in Distribution Using non-dominated Sorting Genetic Algorithm, Electric Power Systems Research, 8.

Le Roux. (2013). Optimisation of Technical Power Losses in Distribution Networks Using Genetic Algorithm and Load Flow. Tshwane University of Technology South Africa.

Mendoza, L.; M. López, and D. Moraga. (2006). Minimal loss reconfiguration using genetic algorithms with restricted population and addressed operators: real application. IEEE transactions on Power Systems, 21(2): 948-954.

Merlin, A. and Back, H. (1975). Search for a minimumloss operating spanning tree configuration in an urban power distribution. Proc. 5th Power System Computation Conf., Cambridge, U.K, 1-18.
Mokhlis, H.; B. Ola.; M. Saad and D. Wardiah. (2017). Optimal reconfiguration of distribution

System connected with distributed generations: A review of different methodologies. Journal of Renewable and Sustainable Energy Reviews, Elsevier Ltd., 73(1): 854-867.

Prasad, K.; R. Ranjan.; N.C. Sahoo and A. Chaturvedi. (2005). Optimal Reconfiguration of Radial Distribution Systems Using a Fuzzy Mutated Genetic Algorithm. IEEE Transactions on Power Delivery, 20 (2): 1211-1213

Rasthechi, V. and Pashai, S. (2012). Network Reconfiguration in Distribution Power system with Distribution Generators for Power Loss Minimization, International Conference on Advance in Computer and Electrical Engineering, Ontario, Canada. 5-10.

Royteleman, I..; V. Melnik.; S. S. H. Lee. and Lugtu. R. L. (1995). Multi-Objective Feeder Reconfiguration by Distribution Management System, IEEE transaction on power delivery, 6 (1):517-522.

Sarfi, J. R.; Sallami, A. M. and Y Chikhani (1994). A Distribution System Reconfiguration for Loss Reduction: A New Algorithm Based on a Set of Quantified Heuristic Rules, IEEE Transaction on Power Delivery, Canadian Conference on Electrical and Computer Engineering. Halifax, Canada

Srinivasa, L. R. and S. V. Narasimham. (2009). A New Heuristic Approach for optimal reconfiguration in distribution system, International Journal of Engineering and Applied Science., 5(1): 7-15.

Tamer, M.; K. Alexander and V. Gorpinich. (2012). Reconfiguration for Loss Reduction of Distribution Systems Using Selective Particle Swarm Optimization, International Journal of Multi-Disciplinary Sciences and Engineering, 3(1):17-18.

Yang, J.; Chengqiang, Z.; Jian, S.; Xu, J. and Qi, J. (2012), The NSGA-II Based Computation for the Multi-Objective Reconfiguration Problem Considering the Power Supply Reliability, China International Conference on Electricity Distribution, Shangai, China. 3(1): 1-5. 